\title{
Pre-Existing Asymmetry of Jaw-Lifting Muscles Revealed by Botulinum Toxin in Treatment of Bruxism
}

\author{
Pierre-Jacques Finiels ${ }^{1 *}$ and Dominique Batifol ${ }^{2}$ \\ ${ }^{1}$ Department of Orthopaedics, Traumatology and Neurological Spine Surgery, Alès General Hospital, France
}

${ }^{2}$ Department of Oral and Maxillofacial Surgery, CHU Montpellier (France)

Submission: October 29, 2017; Published: January 12, 2018

*Corresponding author: Pierre-Jacques Finiels MD, PhD, M Sc, Service de Chirurgie Orthopédique, Traumatologie et Neurochirurgie du Rachis, Hôpital Alès en Cévennes, Avenue du Dr Jean Goubert, 30103 Alès Cedex, France, Fax: +33 466360107; Tel: +33 609347115; Email: dr.pjinielslub@internet.fr

\section{Abstract}

Aim: To confirm a correlation between certain forms of bruxism and asymmetry of the jaw-lifting muscles.

Methods: This was a prospective study, carried out in a single center on a total of 107 patients with severe bruxism, treated with intramuscular botulinum toxin type-A (BoNTA) injections into the masseter muscles. 25 patients demonstrated a clinical and/or electromyographic facial asymmetry of the muscles following botulinum toxin type-A treatment.

Results: The asymmetry appeared after the first botulinum toxin injection in 21 patients. This asymmetry was always correlated with the disappearance of bruxism, predominantly on the right hand side in $60 \%$ of cases.

Conclusion: Certain bruxisms may be due to an asymmetry in tone of the masseter muscles, for which the body compensates by a bilateral muscular spasm. These spasms mask a pre existing asymmetry that can be revealed by muscular relaxation induced by injection of botulinum toxin type-A.

Keywords: Asymmetry; Botulinum toxin type-A (BoNTA); Bruxism; Jaw-lifting; Masseter muscles

\section{Introduction}

Bruxism is a repetitive action characterised by involuntary contraction of the jaw-lifting muscles [1]. It is an oral parafunctional activity thought to affect some $50-95 \%$ of adults. Left untreated, bruxism causes occlusal disease including chips in the teeth, wear of the biting surface, abfractions and cracks in the teeth, and, finally, shortening and blunting of the teeth, leading to pain in the temporo-mandibular joint, or headache in $5-10 \%$ of sufferers. Facial asymmetries have multiple aetiologies: they can be congenital or acquired and can involve the skeleton, the teeth or the muscles, either singly or in combination [2]. During the course of treatment with botulinum toxin type-A (BoNTA), patients suffering from bruxism showed signs of visible and/or palpable muscular asymmetry following relaxation of the jawlifting muscles. BoNTA produces temporary muscular relaxation, but treatment can be repeated as the beneficial effects wane [2]. The aim of this study was to investigate whether a correlation exists between the presence of bruxism and asymmetry of the jaw-lifting muscles.

\section{Materials and Methods}

This was a prospective, single centre study conducted in the Department of Oral and Maxillo-Facial Surgery of Montpellier University Hospital, France, between 2003 and 2016. The study was approved by the local ethics committee and all patients provided written informed consent prior to being enrolled in the study. Study inclusion criteria comprised patients with severe bruxism, regardless of age, who were treated by intra-muscular BoNTA injection into the masseter muscles. Since the cause of bruxism was essentially muscular, the only form of treatment administered was BoNTA. A diagnosis of severe bruxism was reached if patients presented with at least 10 criteria from the classification system established by Molina, Dos Santos, Nelson and Nowlin $[3,4]$. 
The diagnosis was essentially done by palpation of the muscles concerned and electromyographic records. Patients were required to demonstrate absence of visible or discernible facial asymmetry before treatment, as well as an absence of asymmetry from a panoramic scan of the jaw, and so those presenting with both muscle and bone facial asymmetry noted during the clinical examination and panoramic scan of the jaw, or with a neurological disorder detected during the electromyograph (e.g. denervation of the masseters), a history of facial trauma or infection being all excluded from the study.

The injections of BoNTA (BOTOX®: Allergan Pharmaceuticals, Westport, Ireland) were carried out in a symmetrical fashion into the masseter muscles at total doses ranging from $20 \mathrm{U}$ to $50 \mathrm{U}$, the target being the more tense zone at palpation, as confirmed by intra operative electro-myographic recording. The amount of the dose injected was chosen according of results of clinical examination. In addition, injections of up to 20U BoNTA were administered into each temporal muscle in a symmetrical fashion if these muscles showed excessive tonicity. The injection was carried out with the aid of a hollow electrode under audiometric electro-myographic (EMG) control and the time interval between injection sessions was 3 months [5]. Graphic EMG recordings were made using 4 surface electrodes which were placed in order to examine the anterior and posterior regions of the masseters, in association with a frontal neutral electrode. The first graph was recorded with 2 traces positioned left and right which were superimposed to allow comparisons to be made. A recording was then carried out with calculation of the areas under the curve, both sides of the baseline and between strictly identical points on the graph for each of the 2 muscles used to establish the intensity of muscular contraction over time. Using this method, it was possible to determine the differences in intensity of the masseter contractions for an identical period of time. Results were expressed in terms of nanovolts $x$ seconds (nVs) or in microvolts $x$ seconds $(\mu V s)$ (Figure $1 \& 2)$.

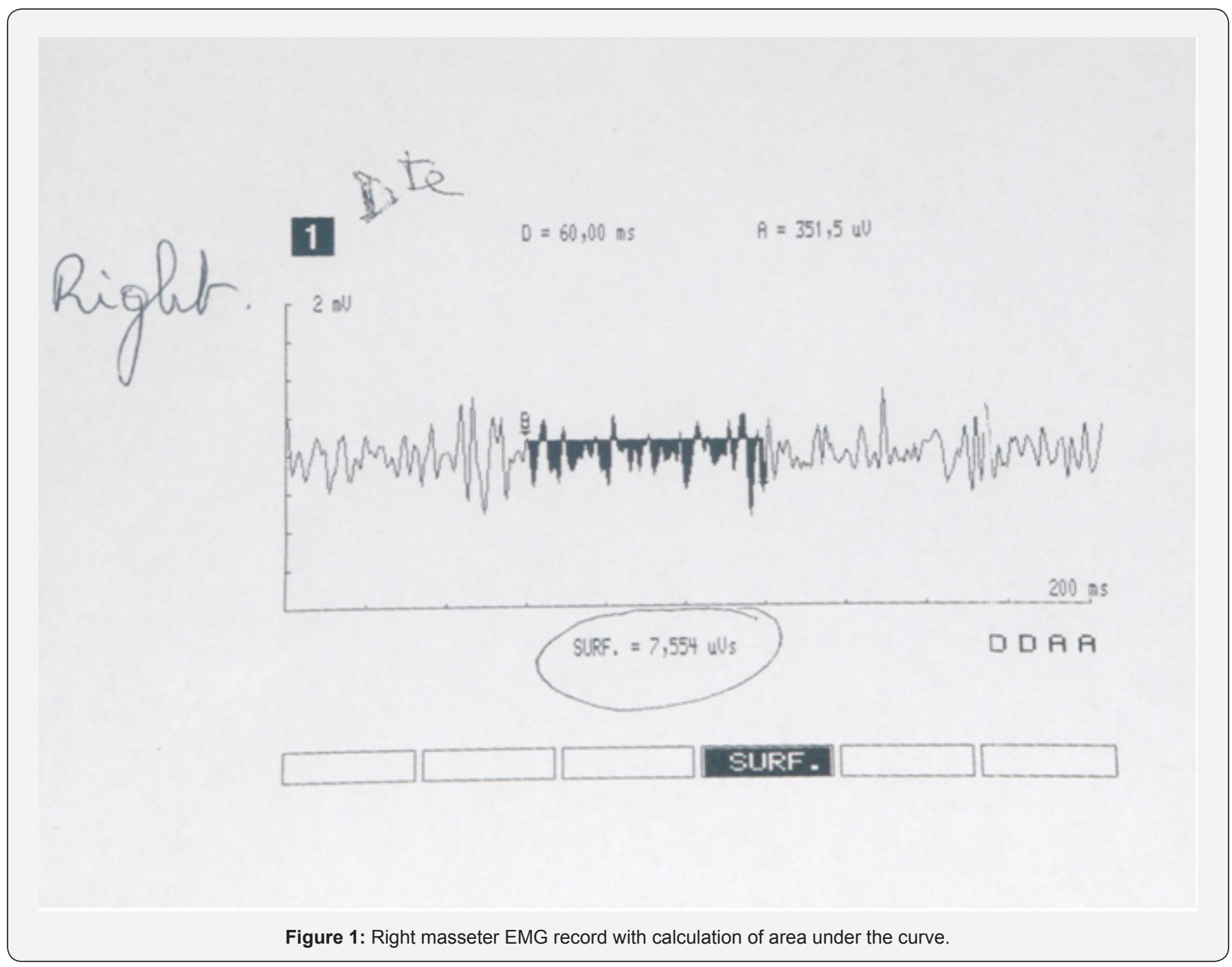




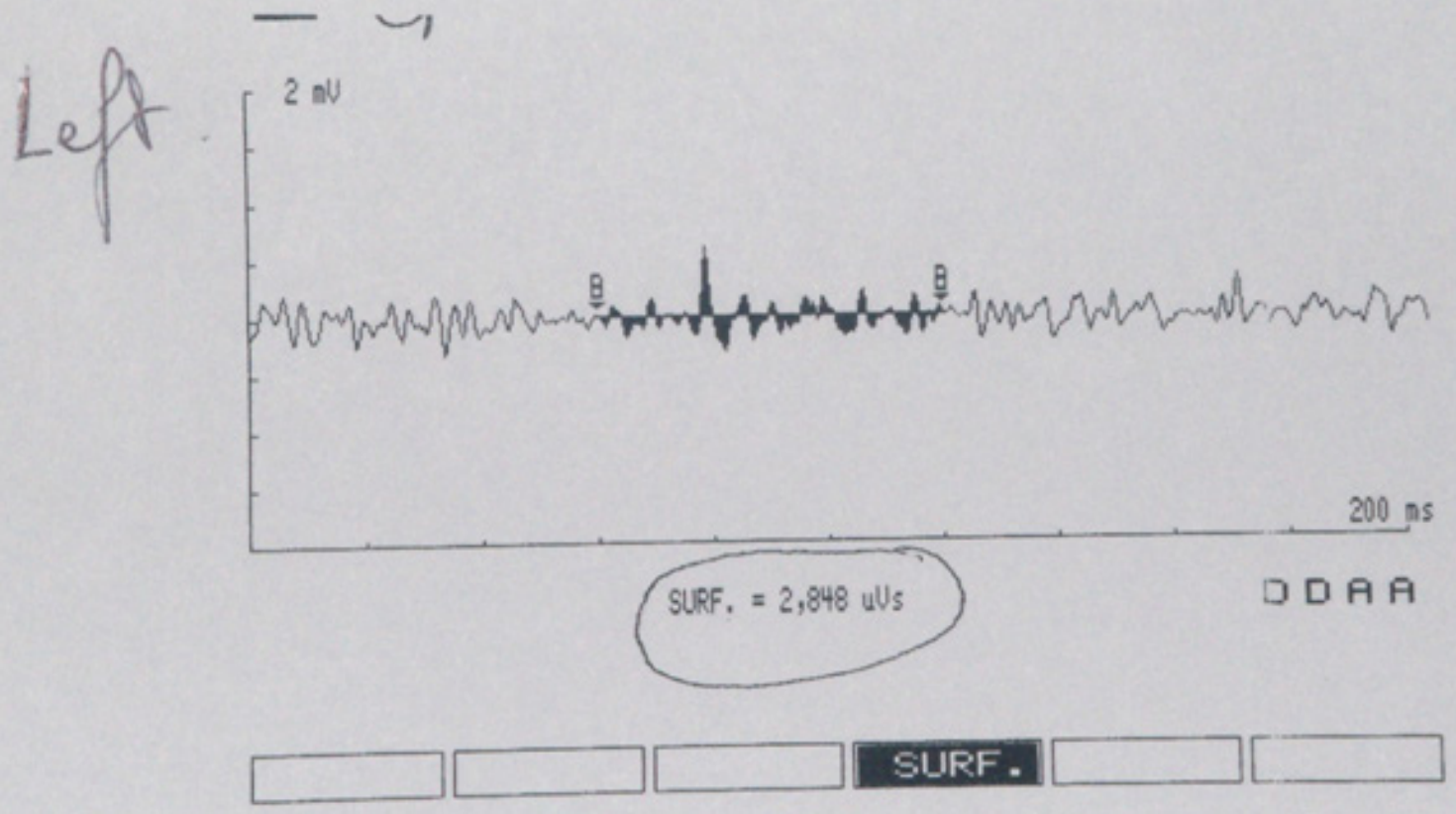

Figure 2: Left masseter EMG record, with calculation of area under the curve in the same patient as in Figure 1. Surface caculated is $2,8 \mu \mathrm{Vs}$ vs $7,5 \mu \mathrm{Vs}$ on the right side. Asymetry is evident.

For each patient, a number of parameters were studied comprising sites of injection, the time taken for the asymmetry to appear, the muscles involved in this asymmetry, the side of hypertrophy and EMG results.

\section{Results}

A total of 107 patients (19 males (17.75\%) and 88 females (82.25\%) who had attended consultation for a jaw dysfunction with bruxism and who was treated exclusively with BoNTA injection was enrolled into the study. Of these 107 patients, 25 (23.4\%) showed notable asymmetry of the masseters following successful treatment of the bruxism. This group comprised 22 females (88\%) and 3 males (12\%) with an average age of 43.5 years (range: 1271 years). 37 patients (34.6\%) were injected solely in the masseter muscles and $70(65.4 \%)$ in both the masseter and temporal muscles. In the patients presenting with an asymmetry, 7 (28\%) were treated with BoNTA injection in the masseters and $18(72 \%)$ in both the masseter and temporal muscles.

With respect to the number of BoNTA injections administered before the appearance of asymmetry, 20 patients $(80 \%)$ presented asymmetry after a single injection, 2 patient (8\%) after 2 injections, and 3 patients (12\%) after 3 injections. For all these patients, the asymmetry involved the masseters and, in 4 cases, the temporal muscles were also involved. Of the 25 patients with asymmetry, 15 patients (60\%) (3 males, 12 females), presented with a larger right-hand side masseter muscle and 10 patients (40\%) (4 males, 6 females) had a larger left-hand side masseter.

The results of EMG recording of the masseter muscles in patients with a clinical asymmetry showed that only 3 female patients did not present an asymmetry, 17 patients ( 6 males, 11 females) presented with a small asymmetry defined as a difference of $\leq 50 \%$ of the surface calculated for each EMG scan (right and left sides) expressed in terms of nVs, and 3 females and 2 males presented with a large asymmetry (defined as a difference of $>50 \%$ ). One patient presented with muscular asymmetry that was clinically discernible without asymmetry evidenced by electrical activity. For 2 patients, the increase was $500 \%$. 


\section{Open Access Journal of Neurology \& Neurosurgery}

\section{Discussion}

The human body is, in general, asymmetric since each muscle has a different volume to its contra-lateral counterpart. Large asymmetries, either congenital or acquired, may be present but do not necessarily cause problems with muscular functioning. Congenital asymmetries are classified as either those that appear during growth, or those which are acquired after growth. A moderate degree of asymmetry is well-tolerated by both the patient and their family, causing no functional or morphological effects [6]. The temporo-mandibular joint (TMJ) has a unique function in the body. Both TMJs are united by the mandibular bone and the TMJs, together with the dental occlusion, form a single functional unit. Significant asymmetries in the jaw-lifting muscles can be the origin of a lack of equilibrium for which the thalamus cannot account. It has been known since the works of Foerster [7] and Head \& Holmes [8] that where there is a duality of sensory information arising from a significant asymmetry, recognition of this information does not extend beyond the thalamus before transmission to the parietal cerebral cortex. The body responds to this disequilibrium by attempting to maintain efficient jaw function and the result is a spasm of the jaw-lifting muscles, thus giving rise to bruxism. In some of our patients, muscular asymmetry was not evident after the first BoNTA injection. However, it should be noted that in these cases the bruxism was not stopped after this single injection, but was subsequently successfully treated after an increase in the injected BoNTA dose, whereupon the asymmetry then became apparent. Follow-up BoNTA injections at 3-monthly intervals ensured continued muscular relaxation, although the clinical and electrical asymmetry persisted.

In some patients with prolonged masseter asymmetry, a technique for protecting masticatory function can be developed as early as infancy that consists of contraction of the masseters through jaw clenching, with or without mandibular propulsion. This technique can be used both for centric or eccentric forms of bruxism. This method is effective but unadvisable because it creates another pathology, which in time can cause masticatory dysfunction. Aetiology of bruxism is incompletely known [1]. Our hypothesis only concerns specific types of bruxisms. Some bruxisms may be due to an asymmetry of the tonicity of the masseter muscles for which the body compensates with a bilateral muscular spasm. This spasm masks a pre-existing asymmetry that is only revealed by muscular relaxation induced by the injection of BoNTA.

In this study, BoNTA injections were administered symmetrically and therefore it was not possible to evoke onesided amyotrophy following the intra-muscular injection of BoNTA. The asymmetry noted once the bruxism was successfully treated always involved the masseter muscles in our study and was the target muscle for BoNTA treatment for all patients. The reason for the masseter muscle involvement in giving rise to asymmetry and bruxism may be due to the strength of this muscle and its key role in occlusion.
In our patients, the appearance of asymmetry was strongly correlated with the disappearance of bruxism, independent of the BoNTA dose administered. Our findings confirm initial results of this study [9], suggesting a relationship between certain bruxisms and asymmetry of the jaw-lifting muscles. In the majority of the cases, the asymmetry was confirmed by EMG and it was therefore not solely a volumetric asymmetry, but also electric, demonstrating both muscular hypertrophy and hyperactivity at the same time [10-13].

In conclusion, bruxism is a common condition, which causes are difficult to establish, but the frequent correlation with muscular asymmetry, evident from the results of this study (23.4\%), after successful treatment of the bruxism with intramuscular BoNTA injections, confirms the importance of the role of asymmetries in the appearance of masseter dysfunction.

\section{Referances}

1. Chikhani L (2002) Dystonie oro-mandibulaire et bruxisme. In: Ranoux D, Gury C (Eds.), Manuel d'utilisation pratique de la toxine botulique. Marseille: Solal, France.

2. Tan E, Jankovic J (2000) Treating severe bruxism with botulinum toxin. J Am Dent Assoc 131(2): 211-6.

3. Moore AP, Moore GDW (1994) The medical management of masseteric hypertrophy with botulinum toxin type. $\mathrm{Br} \mathrm{J}$ Oral Maxillofac Surg 32(1): 26-28

4. Molina OF, dos Santos Junior, Nelson SJ, Nowlin T (1999) A clinical study of specific signs and symptoms of CDM in bruxers classified by the degree of severity. Cranio 17: 268-279.

5. Machida N, Yamada K, Takata Y, Yamada Y (2003) Relationship between facial assymetry and masseter reflex activity. J Oral Maxillofac Surg 61(3): 298-303.

6. Arnaud E, Marchac D, Renier D (2001) Diagnostic d'une asymétrie faciale et crânio-faciale. Ann Chir Plast Esthét 46(5): 410-423.

7. Foerster O (1927) Die Leitungsbahn des Schmerzgefühles und die Chirurgische Behandlung der Schmerzzustände . Urban and Schwarzenberg, Berlin, Germany.

8. Head H, Holmes G (1911) Sensory disturbances from cerebral lesions. Brain 34(2-3): 102-254.

9. Batifol D, Harding-Kaba B, Finiels PJ, Goudot P (2013) Does botulinum toxin reveal pre-existing asymmetry of jaw-lifting muscles in the treatment of bruxism? Pan Arab Neurosurgical Journal 1: 1-14.

10. Chikhani L, Dichamp J (2003) Bruxisme, syndrome algodysfonctionnel des articulations temporo-mandibulaires et toxine botulinique. Ann Readapt Med Phys 46(6): 333-337.

11. Molina O, Dos Santos J (Jr), Nelson SJ, Nowlin T (2000) Profile of DTM and bruxer compared to TDM and nonbruxer patients regarding chief complaint, previous consultations, modes of therapy and chronicity. Cranio 18: 205-219

12. Trawitzki LV, Dantas RO, Mello-Filho FV, Marques W (2006) Effect of treatment of dentofacial deformities on the electromyographic activity of masticatory muscles. Int J Oral Maxillofac Surg 35(2): 170173.

13. Von Lindern JJ, Niederhagen B, Bergé S, Appel T (2003) Type A botulinum toxin in the treatment of chronic facial pain associated with masticatory hyperactivity. J Oral Maxillofac Surg 61(7): 774778. 


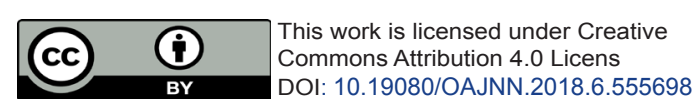

Your next submission with Juniper Publishers will reach you the below assets

- Quality Editorial service

- Swift Peer Review

- Reprints availability

- E-prints Service

- Manuscript Podcast for convenient understanding

- Global attainment for your research

- Manuscript accessibility in different formats

( Pdf, E-pub, Full Text, Audio)

- Unceasing customer service

Track the below URL for one-step submission https://juniperpublishers.com/online-submission.php 